\title{
Integrated School-Based Teacher Education: From Apprenticeship to a Complex Learning System
}

\author{
STEVE COLLINS \& HERMIA TING \\ University of British Columbia (Canada)
}

This article differentiates approaches to school-based teacher education. It contrasts the pervasive apprenticeship model, to a "naturally integrated" school-based teacher education program that we describe as a complex learning system. Rather than view teacher education as fragmented by separating educational theory (physically based on a university campus) and teaching practice (based in a school and resembling an apprenticeship), we favor an approach where all coursework is integrated with practice in a host school while maintaining close connections to the university. The latter model highlights learning as contextualized in school, focused on the whole school, yet also informed by progressive educational thought. All participants in the school environment (not just university students) are at once both learners and teachers.

Just as university-based aspects of teacher education suffer from a lack of practical relevance, we anticipate that any model of school-based teacher education will have to address the effects of context overwhelming theoretical learning, philosophical understandings, and generalization to other contexts. We claim that a complex learning system model is better able to mitigate these contextual effects. We propose an approach to address this issue through both "reduction" and "complexity." 


\section{Introduction}

There is likely no concept that is more maligned in teacher education literature than the separation of theory and practice when preparing new teachers. It is also a concept with strong systemic and political roots in many universities. In spite of an abundance of evidence to support the contrary view, it has remarkable endurance.

Though scholars of teacher education periodically revise the relationship between theory and practice, teacher education programs struggle to redesign programmatic structures and pedagogy to acknowledge and build on the integrated nature of theory and practice as well as the potentially deep interplay between coursework and field placements (Grossman et al., 2009, p. 276).

School-based teacher education refers to teacher education students learning to teach within the context of a public school (as opposed to university classrooms). There have been many efforts to bridge the divide between the theory and practice in teacher education. To add relevance to theory, many teacher educators, including these authors, have moved instruction of teaching theory, strategies, and methods into the context of a school environment. We believe improvement in grounded practice is achieved through this approach. However, a divide remains though the location and focus has changed. Context, indeed because if its relevance, overwhelms big picture thinking and we may be left with deeply contextualized specific practice, which is difficult to transfer over a variety of other settings. There may be advantages to the school-based approach, but our students can still fall short of a complete understanding of how to be outstanding beginning teachers. For the purposes of this article, we define and contrast two implementations of the school-based approach, while recognizing that there are many variations. Through this simplification we hope to illustrate the limitations of the typical training of new teachers by applying separate university course theory instruction to a practicum experience.

This paper is conceptual but the ideas are rooted in experiences with school-based teacher education. It is not intended as our program description but some context is provided to add relevance. One will see that our "complexity view" demands a holistic approach and the writing of this article is no exception to that. It is not written for only an academic audience, though we beg the indulgence of an academic journal as the mediator of our message. Our vision is to celebrate interconnectedness rather than separating the agents affected. We hope that professors, teachers, administrators, new teachers, parents and their children will be able to access at least part of our message. Therefore, hopefully, the language and style of writing is inclusive.

In the following discussion, we provide:

- A theoretical/philosophical/practical grounding for our discussions.

- A brief description of the history for our thinking that grew from the success of a school-based, integrated course that drew on complexity thinking. 
- A review of pertinent literature on school-based teacher education, specifically with regard to the apprenticeship model.

- An argument, using complexity thinking, that all of a teacher education process (including coursework) can be successful when regarding a public school-based host as a complex learning system where all involved are both teachers and learners.

- An effort to address the overwhelming effects of context that occur in both the apprenticeship model and complex learning systems by proposing ways of incorporating complexity that has reductionist aspects to encourage reflective, philosophically-prepared new teachers.

\section{Complexity}

We refer to "complexity" here as a specific way of thinking about living, dynamic, adapting systems. Social systems, such as schools and classrooms are examples. They are quite different than very complicated, mechanical systems that are often colloquially referred to as being complex. That is not how we use the word in describing social, educational systems.

A complex phenomena is irreducible. It transcends its parts, and so cannot be studied strictly in terms of a compilation of those parts. It must be studied at the level of emergence. (Davis, 2003, p. 43)

A complexity view of teacher education focuses on interconnections, responses to interactions, and a dynamic process of adaptation, growth, and learning. In fact, within this view, change is the same thing as learning. "a learning system is any complex form that can adapt itself to changing circumstances" (Davis \& Sumara, 2001, p. 88). This description of learning is nearly identical to the idea of adaptation (at least according to the above authors). We refer to this dynamic in schools, including instances where the university is involved, as complex learning systems. However, "learning" (rather than "adaptation") is a better word to reflect the kind of change that takes place in institutions of education. This language focuses on direct experience and unique understandings. There can be a collective conversation and shared knowledge but the institutionally generalized measures and the attending interpretations of accountability of learning are challenged. A different kind of educational conversation can be started. However, this is also the heart of the inertia that obstructs systemic change. "The process of professional development necessary for the implementation of the realistic approach often takes time. I believe there is no shortcut to fundamental attitudinal change" (Korthagen, 2001, p. 13).

\section{Enacted Learning}

An educational response to complexity, in this sense, is "enactivism." Enacted learning or an enactive approach to teaching, attempts to preserve the interconnections within a complex system. Rather than (or in addition to) the prevalence of "reducing" systems under study into 
smaller parts for separate study, enacted learning undertakes the study of a system in context in the real world where all of the actions, interactions, and interconnections continue to influence everything throughout the whole of the system.

In enactivism, instead of seeing learning as "coming to know", one envisages learner and learned, knower and known, self and other, as co-evolving and being co-implicated. In this situation context is neither the setting for a learning activity, nor the place where the student is, but the student is literally part of the context. (Begg, 1999, p. 72)

Teacher educators continue to try to simplify (reduce) learning to teach by dichotomizing it into theory and practice even though both are simultaneously essential to teaching in a real classroom. Begg (1991) highlights the essential difference between a complexity view of learning and nearly every other conception. Social constructivism, experiential learning, even student-directed learning assume separation of the learner from what is learned and who is learning along with them. Within these conceptions, the idea of apprenticeship can be validated. By contrast, an enacted approach to learning and teaching assumes that learners, teachers, and context are all intrinsically connected to each other. All learning is shared. An apprenticeship, that requires division, cannot stand alone and fully educate our new teachers.

Our view is that the separation, although it can add an uncluttered, narrowed understanding, interferes with relevance, real life problem solving, and a systemic context. Our vision, then, is that all (or nearly all) of a university teacher education process, including coursework, could take place in a public school. While still maintaining access to the wealth of the university's vast resources and expertise, the school context of real teaching and real learning in the real world, can provide a relevant, holistically emerging teacher education.

\section{An Example}

In January of 2012, we had the opportunity to begin a partially integrated school-based teacher education process by teaching two courses at an elementary school for two weeks on a daily basis. Students dubbed the course "The Hamilton Experience" after the name of the school. The courses were Elementary Social Studies Methods and Educational Studies (Issues of Social Justice). The former is a methods course, the latter, highly philosophical and inquiry-based. This was arguably a successful venture that has been chronicled in the BC Teachers Newsmagazine (Collins \& Ting, 2013). We believe that our experience in "complexifying" teacher education at Hamilton School suggested a much more enriching learning environment for our education students in this learning system. From our observations, and based on the comments of teachers and university faculty:

- The coursework was significantly superior to past years of university based Social Studies Methods in terms of both content and creativity.

- The final Expo presentation of students' work was of super quality than of typical university based evidence of learning (according to observer comments).

- Depth of learning and understanding was demonstrated through articulate, indepth explanations by our education students to the visitors at the Expo (Collins \& Ting, 2013). 
Education students themselves supported our conjectures and the opinions of other observers that this success was due to the students' opportunities for grounded planning. In other words, all of their ideas, theoretical understandings, and curricular guidance, were intrinsically connected to specific children in the school and to the feedback they received from the teachers of these children. After The Hamilton Experience, one of our education students, Taryn, commented,

Being on school grounds changed the whole dynamic and atmosphere in a very positive way. Sitting in university classes all day can easily take the focus away from the genuine reason for why we go into teaching. Stressful moments in our portable at Hamilton were easily and immediately extinguished by faint giggles from students outside our window.

Whenever our education students had an idea or a question, they could check in with the real experts: the kids.

There were many anecdotal accolades that can be variously interpreted. There were also limitations and significant challenges, some of which are noted in the aforementioned article by Collins and Ting (2013). Of particular concern to us as course instructors was that although theoretical and philosophical concepts could be readily contextualized, often they were not. The practical part of teaching continued to be the main focus and reflective thought still had to be encouraged - or even demanded. The divide, though mitigated, still remained.

\section{Apprenticeship}

The most familiar application of school-based teacher education is an apprenticeship model that generally refers solely to the teaching practicum and is intended to add context to theoretical coursework that is carried out on a distant university campus. For example, on the website for our teacher education program at the University of British Columbia, the practicum is described as follows:

The teaching practicum is an exciting part of the Bachelor of Education program because it is the time when teacher candidates put theory into practice alongside an experienced teacher. Initially, emphasis is placed on gradual orientation to the school setting. After this acclimatization period, the focus shifts to meeting the challenges of an increased teaching load and added responsibilities. (Teacher Education Office, University of British Columbia, 2014)

This seems to be a typical description of the ubiquitous apprenticeship model for a teacher education practicum. Theory is hopefully applied to practice. Instructing education students to teach is a top-down, master to student transmission of knowledge.

In the case of the apprenticeship model, all too often, what is learned is an everyday pedagogy of 'showing and telling', in which the underlying principles are not made explicit and learning occurs through imitation and adaptation. Underlying principles often remain unaddressed and, if they are addressed, are not always theoretically underpinned. This danger is exacerbated because implicit learning about the profession constitutes a significant part of school-based learning to teach. In the implicit learning process, teachers and student teachers learn how to teach without being conscious of it, let alone of how they mastered the skill. (Buitink, 2009, p.118) 
The apprenticeship model for teacher education has come under criticism, largely, we believe, because of a contrived reduction of the complex interplay in classrooms. This preserves a simple, dichotomous model, separating the education student's role from that of the advisor.

Jean Lave and Etienne Wenger (1991), in their book Situated Learning: Legitimate Peripheral Participation, eloquently articulate the basis of our conceptual work:

If apprenticeship is a form of education in which work and learning are seamlessly related, it is nonetheless a form in which the work and the understanding of newcomers bear complex and changing relations with ongoing work processes; the structure of production and the structure of apprenticeship do not coincide as a whole.... This has interesting, also complex, implications for the processes of deepening and changing understanding for all members of a community of practice. (p. 86)

As well, education students are not aware of prior events, discussions, and decision that determined the current state of the way things are in schools or in education. The underlying reasons for why things are the way they are, are often outside of the direct context of the concrete teaching setting in the apprenticeship model. In a complex learning system, these systemic roots of instruction and depth of thought can be made explicit by instructors and teachers when deliberately associated with the context of classroom teaching.

\section{The Complexity View}

A significantly different way to envision teacher education is as a naturally integrated schoolbased teacher education process. It regards schools that host teacher education students as "complex learning systems". This teacher education process, including coursework, is carried out at the school level with strong connections to university resources and expertise.

On one hand, we may carry on the practical work with the object of giving teachers in training working command of the necessary tools of their profession; control of the technique of class instruction and management; skill and proficiency in the work of teaching. With this aim in view, practice work is, as far as it goes, of the nature of apprenticeship. On the other hand, we may propose to use practice work as an instrument in making real and vital theoretical instruction; the knowledge of subject-matter and of principles of education. (Dewey, 1904, p. 1)

The apprenticeship model ignores the complexity of all of the interconnections available within a school environment, which could actually be used to enhance learning throughout the school. It is possible that teacher education, child education, professional development, an opportunity for research, and much more, could all interact cohesively within the same interconnected environment. There is an opportunity for integration among subjects to arise naturally rather than being contrived and pre-planned to fulfill some popular pedagogy for integration. Indeed, when courses are separated into faculty department areas on campus, planning for integration is hampered from the start.

As well, the top-down linear approach perpetuates the outdated idea that knowledge and learning are directed by teachers while students are passive recipients. There are few current educators who still adhere to this pedagogy, yet this kind of thinking still underlies teacher education within an apprenticeship model. We envision enacting all coursework as practice, inquiry, content, and reflection, within a school. 
In a complex learning system, all agents are interconnected contributors. Everyone is learning. We move away from the unidirectional, traditional system of professor imparting knowledge to education students, who then go to the field and become directed by a classroom teacher like an apprentice. Rather, professors will teach with an attitude that is responsive rather than controlling. They constantly learn how to instruct from student feedback, inviting teacher input into course pedagogy, and collecting the ideas and examples that are acquired in this immersed situation.

In regarding school-based teacher education programs as complex systems, we see potential gains for all involved. As always, education students learn from advisors and instructors and elementary school students still learn with excitement from enthusiastic education students. Clearly, it is equally important to realize that education students also learn from the responses of the children. Teachers also learn from their education students when they are willing to use the opportunity to develop professionally (the latest educational practice and thought, new technical development, and an opportunity to learn and practice new curricula). For academics, with close connections to the university, opportunities for research are welcomed.

Learning should not be understood in terms of a sequence of actions, but in terms of an ongoing structural dance - a complex choreography - of events which, even in retrospect, cannot be fully disentangled and understood, let alone reproduced. (Davis, Sumara and Kieren, 1996, p. 153)

A complex learning system is based on interconnections among content, philosophies, strategies, curriculum, teachers, students, and all other possible agents. Growth and adaptation depends on constant interaction among all participants.

Hence our efforts to understand the world are perhaps better thought of in terms of interpreting our own perceptions and patterns of acting within a dynamic context than in terms of coming to know that context is somehow independent of our participation. (Davis, 1996, p. 14)

\section{Context Overwhelms Systemic Thinking}

We agree with the educational writers above (Dewey, 1904; Davis et al., 1996) regarding the issues of relevance in a teacher education practicum. These issues, among others, are "realness", interconnectedness, and direct participation. Further, contextualized learning to teach, whether it is in an apprenticeship or another school based model, can tend to focus mainly on the immediate, the practical, the specific, and lose the overarching coherence provided by general principles. The learning environment can well consume education students' awareness as they intently attend to the needs of their own students, the guidance of their mentors, and the impact of constantly adapting to the school's evolving demands in any school-based experience.

In the case of a complex learning system, it is important to realize that being immersed directly in complexity can also be extremely distracting. In our explorations of the matter (Collins \& Ting, 2013, p. 6), we were once tempted to assume that with coursework integrated within a complex learning system model, the loss of abstract thinking might be avoided since these principles were introduced with immediate examples. However, when it came time for 
students to explore big picture aspects of social justice in this contextualized environment, they were very adept at reporting back what they could observe directly. Yet they could not theorize, imagine, or speculate on root causes pertaining to these observations. Philosophical and abstract thought was overwhelmed by direct experience and guidance was required. One of our education students, Rachel, put it well,

It's so easy to talk about complexity when all you have to look at is four walls and a PowerPoint on a screen. But when you get into the real world, and actual living, breathing children are capturing your attention there is just too much to take in all at once! I think we all just forgot to stop and try to "think big", because it was all we could do to take in what was going on around us!

Instructors were required to ensure that explicit reflective processes were practiced with education students in order to raise their consciousness above their immediate senses.

The student adjusts his [sic] actual methods of teaching, not to the principles that he is acquiring, but to what he sees succeed and fail in an empirical way from moment to moment; to what he sees other teachers doing who are more experienced and successful in keeping order than he is; and to the injunctions and directions given to him by others. In this way, the controlling habits of the teacher finally get fixed with comparatively little reference to the psychological, logic, and history of education. (Dewey, 1904, p. 14)

We speculated about whether or not this could be the very reason abstract thought has traditionally been artificially detached from the distractions of practice when we guide new teachers into our profession.

Now, within the perspective of complexity thinking, that divide seems to be an extreme dichotomous response to distracting contexts which are present in all approaches to schoolbased teacher education.

We now present an approach that:

- Integrates reductionist strategy and holistic practice,

- Uses of the concept of "self-similarity" as a teaching tool, and

- Provides a specific example from the authors' practice.

\section{Embedding Reductionism within Complexity}

Gert Beista and Deborah Osberg (2010) describe complexity reduction in a way that might be a surprising perspective for those living in a mechanistic reality that is normal in modern schools and universities:

Despite the complex, recursive, and non-linear character of educational processes, there is a substantial amount of order and regularity in education. Whereas from a non-complexivist perspective this would be taken as the normal state of affairs so that the task would be of accounting for non-linearity and unpredictability, from a complexivist perspective it is actually the emergence of order and predictability that requires explanation. (p. 2) 
We see the utility of the common practice throughout our society of reducing complex systems into arbitrary simple frameworks - partially and temporarily. This practice of reductionism can indeed focus attention on smaller more easily understood parts.

I do not wish to suggest that the dichotomies that we construct and through which we make sense of the world are unhelpful, but that they should not be regarded as absolute.... I invoke the pragmatist measure of truth and argue that such constructions are valid insofar as they are useful. (Davis, 1996, p. 2)

Part of learning to teach is to understand the interplay between theory and practice. An opportunity for both to co-exist simultaneously provides relevance and cohesion. We think it is still much better to try to resolve the issue of distraction by guiding our students to a better understanding of the complexity of a school environment. Rather than removing the wealth of interconnections by enshrining the theoretical within the academy and exporting the practical to an apprenticeship model at a school, we feel there could be a unifying approach that both embraces complexity and contextualizes all aspects of learning to teach.

Temporarily reducing complexity for our students at key times to increase focus on salient general issues of teaching and learning can provide insight into both overarching principles and specific practice when context is not so far away.

Complexity theory suggests that order can be achieved - or can become more likely - through the reduction of complexity, for example by limiting the number of possible variables or by reducing the "recursivity" of the system. It thus provides a different outlook on the question of the creation of educational order (Biesta \& Osberg, 2010, p. 2).

\section{Self-Similar Connections Among Theories and Practices}

In an attempt to highlight connections among present context, historical evolution of practice, and progressive educational thought, we designed an activity for a school-based course that integrated social studies and educational studies. As mentioned, the former is a very practical methods-based course and the latter highly conceptual. Once again the nature of the combination led us to enact instruction contextually and reflectively at once. This activity involved the normally reductionist practice of categorization, but was undertaken within the complexity concept of self-similarity or nestedness.

Self-similarity is a concept that is most prevalent in mathematics with the study and construction of fractals. However, it has been observed that natural systems are self-similar as well. Fritjof Capra (1982) spoke of system levels in trees. He described the interconnections and interdependencies among all system levels. "The trunk of the systems tree indicates that the individual organism is connected to larger social and ecological systems, which in turn have the same tree structure" (p. 282).

Just as a branch of a tree looks like the whole tree, we also see that social systems, like all complex systems are self-similar. This nestedness is evident in a school where the same social 
structures influence a child, within a classroom, within a school, within a community, and so on.

Complex adaptive systems are nested. That is, they are interconnected with other larger macrosystems or smaller subsystems. (Gunther \& Folke, 1992, p. 265).

The various systems are themselves dynamic and are in continuous interaction with each other. For example, classrooms are subsystems within a whole school system, which in turn is a subsystem of a state or national educational system. The educational, social, political, and physical variables within a classroom interconnect with those in 'higher' (social-semiotic) and 'lower' (e.g., chemical, physical, and biological) systems and interact with them. (Lemke, 2002, p.

The following is a specific case of integrating general and specific thinking beyond merely adding mandated reflection onto an apprenticeship. We used this idea of self-similarity with our education students to help them see the connections of the specific and concrete to big picture systemic thinking. We reduced the complexity of their local experience into three categories: classroom, school, community. We illustrated how these three systems are nested by sharing a visual that consisted of three concentric circles. In the center of the smallest circle was "classroom." It was surrounded by "school", which was surrounded by "community." Our students went off to see what characteristics of the neighboring community might influence school policy which, in turn, would influence events in the classroom. For example, our education students might find that there was a lower socio-economic status in much of the neighborhood. Inside the school, they would see a hot lunch program. In the classroom, they would see that all students had healthy meals at lunchtime, meaning that they could all focus well on their school work in the afternoon.

By temporarily reducing the complex school environment, yet preserving the interconnections, education students could gain a better perspective on how greater social conditions, create school policy, which determines optimal learning in the classroom.

We reduced our perspective and narrowed the focus of our students. This can be scaled up or scaled down depending on the purpose at the time. Moving up the scale, we can add the influences of city factors, provincial politics (in Canada), or national policy. Moving down the scale is very interesting indeed, because it requires our new teachers to focus on individual students and how they are influenced - or not influenced - by the factors above and below them on the scale. This exercise will be powerful tool for differentiating instruction. They may see how common events can affect individuals differently.

This kind of reduction can also be tailored to many conceptual topics. For example, we had our students do the same activity to give perspective on how philosophy and theory affect their methodology, which then addresses the content across many topics and disciplines. The exercise gave education students a much clearer idea of how the interplay of both theory and 
practice is essential to teaching. This is typically less clear in an isolated university classroom and can breed a disdain for anything that is "not practical" - a very damaging viewpoint when expecting effective, wellconsidered teaching regardless of the setting.

Reductionism is not the opposite of complexity. That would be a dichotomy in itself. Rather, reductionism is part of complexity and it is what we do to make sense of the world. A school-based approach to teacher education should enhance the utility of reductionism without losing the advantages of embeddedness in a complex learning system.

\section{Conclusion}

We believe that the division between theory and practice as carried out with an apprenticeship model has been criticized from a pedagogical perspective and have cited a few authors with similar views. We recognize that school-based teacher education that includes, or even enacts coursework, in itself, is not a new proposal nor an especially innovative practice. We also note that the dichotomy between the academy and site of practice persists. We suspect that this policy is efficient and probably cost-effective. There are control structures in place among faculty departments that are resistant to blurring the boundaries among subject areas.

In his pursuit of the "realistic teacher education," Fred Korthagen (2001) cites many authors whose research finds flaws in the common way of thinking about education. He says that "as soon as teacher educators start to change and become willing to adopt the realistic approach, they are confronted with institutional barriers that are sometimes hard to overcome" (p. 13).

There currently is a systemic preference to divide theory and practice, regardless of pedagogy, empirical evidence, and descriptive accounts that suggest more effective structures. Schoolbased approaches can fit into this divide if they restrict themselves to the practice side with the teaching practicum. This results in the apprenticeship model with all of its difficulties, but clearly necessary within the mandated dichotomy.

We propose a change in thought and implementation in teacher education that embraces the complexity within social systems. We hope to prepare teachers to excel and teach effectively within the complex social system of any public school.

This changes the top-down approach of the apprenticeship model. Instead, it turns teaching into a network. Attention is needed to make sure the processes of higher level thinking continue 
within the school context. If we ensure this happens for our education students, we believe there is potential for it will happen with their intrinsically connected partners and mentors. Learning to teach while teaching to learn will take place for all within a complex learning system.

\section{References}

Begg, A. (1999). Enactivism and Mathematics Education. MERGA. 22, 68 - 75.

Biesta, G. \& Osberg, D. (2010). Complexity, Education and Politics from the Inside-Out and the Outside-In, In Osberg \& Biesta (eds), Complexity Theory and the Politics of Education. Rotterdam, The Netherlands: Sense Publishers.

Buitink, J. (2009). What and how do student teachers learn during school-based teacher education. Teaching and Teacher Education, 25(1), 118-127.

Capra, F. (1982). The Turning Point. New York, New York: Simon and Schuster.

Collins, S. \& Ting, H. (2013, March). The rEvolution: A beginning. British Columbia Teachers' Federation Teacher Newsmagazine. Retrieved from https://bctf.ca/publications/NewsmagArticle.aspx?id=29355

Davis, B. (1996). Teaching Mathematics: Toward a Sound Alternative. New York: Garland Publishing, Inc.

Davis, B. (2003). Toward a pragmatics of Complex transformation. Journal of the Canadian Association for Curriculum Studies, 1(1), 39-45.

Davis, B., \& Sumara, D. (2001). Learning communities: understanding the workplace as a Complex system. New Directions for Adults and Continuing Education, 92(2), 85-95.

Davis, B., Sumara, D, and Kieren, T.E. (1996). Cognition. co-emergence, curriculum. Journal of Curriculum Studies. 28(2), 151 - 169.

Dewey, J. (1904). The Relation of Theory to Practice in Education. The Middle Works of John Dewey. Southern Illinois University Press.

Grossman, P., Hammerness, K. \& McDonald, M. (2009). Redefining teaching, re-imagining teacher education, p. 273-289.

Gunther F., \& Folke, C. (1992). Characteristics of nested living systems. Journal of Biological Systems, 1(3), 257274.

Korthagen, F. (2001). Linking Theory and Practice: The Pedagogy of Realistic Teacher Education. London: Laurence Erlbaum Associates, Publishers.

Lave, J. \& Wenger, E. (1991). Situated Learning: Legitimate Peripheral Participation. New York: Cambridge University Press.

Lemke, J. L. (2002). Language development and identity: Multiple timescales in the social ecology of learning. In C. Kramsch (Ed.), Language acquisition and language socialization: Ecological perspectives (pp. 68-87). London: Continuum.

Teacher Education Office, University of British Columbia. (2014). http://teach.educ.ubc.ca/bachelor-ofeducation-program/practicum/tc-information

\section{About the Author/s}

Steve Collins is an Instructor at the University of British Columbia in the Faculty of Education. He has a Ph.D. in curriculum studies and specializes in the fields of complexity thinking and democratic classrooms. His 25 years of teaching at the university have overlapped with 34 years teaching in public elementary schools. steve.collins@ubc.ca

Hermia Ting is a Teacher in the Richmond, British Columbia public school system and has been teaching for 10 years. She received her Master of Educational Technology in 2011. She has an interest in educational reform in 
both teacher education and public schooling. She has co-instructed university teacher education courses, presented workshops to teacher education students, and assisted with their practica. hting@sd38.bc.ca

(C) Copyright 2017. The authors, STEVE COLLINS \& HERMIA TING, assign to the University of Alberta and other educational and non-profit institutions a non-exclusive license to use this document for personal use and in courses of instruction provided that the article is used in full and this copyright statement is reproduced. The authors also grant a non-exclusive license to the University of Alberta to publish this document in full on the World Wide Web, and for the document to be published on mirrors on the World Wide Web. Any other usage is prohibited without the express permission of the authors. 